\title{
Short communication: Genetic relationships between claw disorders, protein yield, and somatic cell score by days in milk
}

\author{
E. Gernand* and S. Königt ${ }^{1}$ \\ ${ }^{*}$ Thuringian State Institute of Agriculture, 07743 Jena, Germany \\ †Department of Animal Breeding, University of Kassel, 37213 Witzenhausen, Germany
}

\begin{abstract}
The aim of the present study was to infer daily genetic relationships between the selected claw disorders digital dermatitis, sole ulcer (SU), and interdigital hyperplasia ( $\mathrm{IH}$ ) and protein yield and the udder health indicator somatic cell score (SCS). Data were from 26,651 Holstein cows kept in 15 selected largescale herds located in the region of Thuringia in the eastern part of Germany. Herds are characterized by organized data recording for novel health traits, and for the present study, claw disorders from the years 2008 to 2012 were used. A longitudinal and binary health data structure was created by assigning claw disorders to adjacent official test days. No entry of a claw disorder within a given interval of approximately $30 \mathrm{~d}$ implied a score of 0 (healthy), and otherwise, a score of 1 (diseased). Threshold random regression models (RRM) were applied to binary health data, and linear RRM to Gaussian-distributed protein yield and SCS. Genetic correlations between protein yield and SCS for identical days in milk (DIM) only revealed a tendency for genetic antagonisms between DIM 40 and DIM 180, with a maximal genetic correlation $\left(\mathrm{r}_{\mathrm{g}}\right)$ of 0.14 at DIM 100 . With regard to protein yield and claw disorders, the largest and moderate values of $\mathrm{r}_{\mathrm{g}}(\sim 0.30)$, indicating a genetic antagonism between productivity and claw health, were found when correlating protein yield from DIM 300 with SU from DIM 160. Especially for SU and protein yield, time-lagged relationships were more pronounced than genetic relationships from the same test days. Genetic correlations between IH and protein yield were favorable and negative from calving to DIM 300. Generally, on the genetic scale, we found heterogeneous associations between protein yield and claw disorders (i.e., different $r_{g}$ at identical test days for different claw disorders, and also an alteration of $r_{g}$ for identical traits at different DIM). The SCS measured at d 20, 160, and 300 was genetically positively correlated with SU over
\end{abstract}

Received October 16, 2013.

Accepted May 13, 2014.

${ }^{1}$ Corresponding author: sven.koenig@uni-kassel.de the whole trajectory of $365 \mathrm{~d}$, indicating a common genetic background for claw and udder health. A maximal value of 0.36 was found for the $r_{g}$ between SCS from d 300 and SU early in lactation. Additionally, a recursive effect was observed (i.e., $\mathrm{r}_{\mathrm{g}}=0.26$ between SCS from d 20 and SU from d 340). Genetic correlations between SCS and IH, and between SCS and digital dermatitis, were close to zero and partly negative during lactation. Results showed the feasibility of threshold RRM applications to binary claw health data, and a changing genetic background in the course of lactation. From a practical perspective, and with regard to the herds used in this study, continuation of breeding on productivity will have different effects on incidences of different claw disorders, with the highest susceptibility to SU.

Key words: random regression model, claw disorder, protein yield, somatic cell score

\section{Short Communication}

Genetic associations between claw health, productivity, and udder health have been studied by using single test-day observations for production traits from different lactation stages (e.g., König et al., 2008), using an average from several test days (e.g., Koenig et al., 2005), or using lactation records (e.g., Lyons et al., 1991). In those studies, mostly antagonistic relationships between claw disorders and milk or protein yield were identified. Furthermore, genetic correlations $\left(\mathbf{r}_{\mathrm{g}}\right)$ between claw disorders and the udder health indicator SCS were positive, indicating that the same cows are susceptible to both categories claw and udder infections. Nevertheless, interpretation of $r_{g}$ between health and productivity is complicated due to the role of cause and effect. To infer relationships by depicting the physiological background, recursive models based on only 2 observations for test-day data and a single observation for claw health per cow were used (König et al., 2008). The application of random regression models (RRM) to both types of traits Gaussian-distributed test-day production records and binary claw disorders implies the consideration of all available observations in the course of lactation. Genetic correlations within 
Table 1. Mean incidences for claw disorders and means for protein yield and SCS for different test days ${ }^{1}$ in the course of lactation

\begin{tabular}{|c|c|c|c|c|c|c|c|c|c|c|c|c|}
\hline Item $^{2}$ & \multicolumn{12}{|c|}{ Test day } \\
\hline \multicolumn{13}{|l|}{ Claw disorder } \\
\hline $\mathrm{SU}$ & 1.55 & 1.77 & 1.93 & 1.83 & 1.95 & 1.61 & 1.53 & 1.50 & 1.30 & 1.24 & 0.98 & 0.78 \\
\hline $\mathrm{IH}$ & 2.38 & 0.89 & 0.69 & 0.63 & 0.75 & 0.70 & 0.71 & 0.72 & 0.69 & 0.80 & 0.71 & 0.68 \\
\hline Protein yield & 1.03 & 1.11 & 1.13 & 1.12 & 1.09 & 1.05 & 1.00 & 0.95 & 0.88 & 0.73 & 0.55 & 0.47 \\
\hline
\end{tabular}

and between traits for all combinations of DIM allow a differentiated interpretation of associations on the genetic scale (e.g., to study the effect of high genetic merit for protein yield directly after calving on disease susceptibility, or to analyze the effect of a claw disorder on productivity in the ongoing lactation).

Recently, a changing genetic background with changes in variances and variance ratios for claw disorders by DIM was shown by Gernand et al. (2013). Additionally, they estimated $r_{g}$ between claw disorders and linear type traits. The largest, but only moderate estimates were found when correlating measurements from the same day. Genetic correlations between claw disorders and linear type traits from test days further apart were close to zero. Results indicated that type traits routinely recorded approximately 2 mo after calving are only weak predictors for claw health in very early or late lactation. In consequence, the aim of our present study was the extension of the RRM approach by additionally including test-day protein yield and test-day SCS. In detail, we studied genetic associations between claw disorders with test-day protein yield, between claw disorders and test-day SCS, and between test-day protein yield and test-day SCS for all combinations of DIM over a period of $365 \mathrm{~d}$.

Data recording included 26,651 Holstein cows from parities 1, 2, and 3, and spanned a period from 2008 to 2012. Cows were kept in 15 large-scale cooperator herds in the region of Thuringia located in the eastern part of Germany. Data preparation for creating a longitudinal data structure by assigning claw disorders to the nearest official test day was identical, as described by Gernand et al. (2013). Such a strategy for data preparation resulted in 406,327 test-day records for all traits, including 184,404 test-day records from parity 1 , 135,685 test-records from parity 2, and 86,234 test-day records from parity 3 . Sires had, on average, 21 daughters per sire, and 74 sires had more than 60 daughters. Recording of claw disorders was based on the diagnosis key by Feucker and Staufenbiel (2003). The focus of the current study was on the purulent claw disorders digital dermatitis (DD) and sole ulcer (SU), and on the nonpurulent claw disorder interdigital hyperplasia (IH). Decision of claw disorder selection was based on incidences and heritabilities. In the study by Gernand et al. (2013), SU and DD had the highest incidences, with 10.54 and $12.52 \%$ on a lactation level, respectively, and heritabilities were low to moderate. For IH, the lactation incidence was quite low $(5.62 \%)$, but the highest heritabilities, with estimates up to 0.35 , were found. Mean incidences on the test-day scale for the 3 claw disorders DD, SU, and IH are summarized in Table 1.

Threshold RRM for binary health traits and linear RRM for protein yield and SCS were used to infer genetic (co)variance components for all combinations of test-day traits with claw disorders, and for protein yield with SCS, resulting in 7 bivariate runs (6 bivariate threshold-linear models, and 1 linear-linear model). The statistical models in matrix notation were defined as follows:

$$
\begin{aligned}
& \mathbf{l}=\mathbf{X} \boldsymbol{\beta}+\mathbf{Z u}+\mathbf{W} \mathbf{p e}+\mathbf{e} \\
& \mathbf{y}=\mathbf{X} \boldsymbol{\beta}+\mathbf{Z u}+\mathbf{W} \mathbf{p e}+\mathbf{e}
\end{aligned}
$$

where $\mathbf{l}=$ vector of unobserved liabilities for claw disorders with the binary outcome $1=$ diseased or $0=$ healthy; $\mathbf{y}=$ vector of phenotypic observations for the Gaussian traits protein yield and SCS, and vector of liabilities for binary traits DD, SU, and IH; $\boldsymbol{\beta}=$ vector of fixed effects, including the combined effect of herd-test date-milking frequency and regressions on DIM within parity using fourth-order Legendre polynomials; $\mathbf{u}=$ vector of random additive genetic effects, with regressions on DIM using fourth-order Legendre polynomials; pe $=$ vector of permanent environmental effects, with regressions on DIM using fourth-order Legendre polynomials; $\mathbf{e}=$ vector of random residual effects; and $\mathbf{X}, \mathbf{Z}$, and $\mathbf{W}$ are the associated incidence matrices, respectively. For the application of Legendre polynomials, 
Table 2. Posterior daily heritabilities for claw disorders, protein yield, and SCS at selected DIM from all realized bivariate models (SD of posterior heritabilities were $<0.01)$

\begin{tabular}{|c|c|c|c|c|c|c|c|c|}
\hline \multirow[b]{2}{*}{ Trait $^{1}$} & \multirow[b]{2}{*}{ Bivariate model with } & \multicolumn{7}{|c|}{ DIM } \\
\hline & & 6 & 20 & 100 & 160 & 200 & 300 & 360 \\
\hline DD & Protein yield & 0.29 & 0.24 & 0.16 & 0.16 & 0.15 & 0.13 & 0.19 \\
\hline DD & SCS & 0.28 & 0.23 & 0.17 & 0.17 & 0.16 & 0.12 & 0.16 \\
\hline SU & Protein yield & 0.21 & 0.18 & 0.18 & 0.16 & 0.13 & 0.13 & 0.20 \\
\hline SU & SCS & 0.21 & 0.18 & 0.18 & 0.16 & 0.14 & 0.15 & 0.18 \\
\hline Protein yield & $\mathrm{DD}$ & 0.16 & 0.14 & 0.15 & 0.20 & 0.24 & 0.35 & 0.39 \\
\hline Protein yield & $\mathrm{SU}$ & 0.16 & 0.14 & 0.15 & 0.21 & 0.24 & 0.35 & 0.39 \\
\hline Protein yield & $\mathrm{IH}$ & 0.16 & 0.14 & 0.15 & 0.20 & 0.24 & 0.35 & 0.39 \\
\hline Protein yield & SCS & 0.16 & 0.13 & 0.15 & 0.20 & 0.24 & 0.34 & 0.39 \\
\hline SCS & $\mathrm{DD}$ & 0.10 & 0.10 & 0.10 & 0.11 & 0.11 & 0.11 & 0.13 \\
\hline SCS & $\mathrm{SU}$ & 0.10 & 0.10 & 0.10 & 0.11 & 0.11 & 0.11 & 0.13 \\
\hline SCS & $\mathrm{IH}$ & 0.10 & 0.10 & 0.10 & 0.11 & 0.11 & 0.11 & 0.12 \\
\hline
\end{tabular}

${ }^{1} \mathrm{DD}=$ digital dermatitis; $\mathrm{SU}=$ sole ulcer; $\mathrm{IH}=$ interdigital hyperplasia.

DIM were standardized in the interval from $6 \mathrm{~d}$ to 365 $\mathrm{d}$ after calving. The (co)variance structure of random effects was as follows:

$$
\operatorname{var}\left[\begin{array}{c}
\mathbf{u} \\
\mathbf{p e} \\
\mathbf{e}
\end{array}\right]=\left[\begin{array}{ccc}
\mathbf{G} \otimes \mathbf{A} & 0 & 0 \\
0 & \mathbf{P} \otimes \mathbf{I}_{\mathbf{p e}} & \\
& & \mathbf{R} \otimes \mathbf{I}_{\mathbf{n}}
\end{array}\right],
$$

where $\mathbf{G}=$ (co)variance matrix of random regression coefficients for direct genetic effects by DIM; $\mathbf{A}=$ additive genetic relationship matrix among animals using the full relationship matrix of a pedigree that includes 57,038 different animals traced back to 4 generations; $\mathbf{P}=($ co) variance matrix of random regression coefficients for permanent environmental effects by DIM; $\mathbf{I}_{\mathrm{pe}}$ $=$ identity matrix for cows, $\mathbf{R}=$ (co)variance matrix for residual effects, $\mathbf{I}_{\mathbf{n}}=$ identity matrix for $\mathrm{n}$ observations, and $\otimes=$ Kronecker product.

Analyses were done in a Bayesian framework by applying Gibbs sampling and using the software package DMU (Madsen and Jensen, 2008). Based on previous experience with genetic analyses on health traits and on visual inspections of the trace plots for genetic covariances, a chain length of 300,000 samples was assessed and 50,000 samples were discarded as burn-in phase. Consequently, posterior statistics for genetic parameters were based on 250,000 samples.

Heritabilities for the claw disorders DD, SU, and $\mathrm{IH}$ in the course of lactation (i.e., marginally higher heritabilities directly after calving and at the end of lactation; Table 2) were identical, as reported by Gernand et al. (2013), for estimates from univariate runs. A marginally different shape of heritabilities by DIM was observed for test-day protein yield and test-day SCS. For protein yield, heritabilities continuously increased from 0.16 in the early period after calving to 0.39 at DIM 365. The study by Gernand et al. (2007) only focused on the estimation of genetic parameters for test-day production traits by applying RRM. Using a similar subset of herds from the initial phase of the "cooperator herd system," heritabilities for protein yield were largest in the middle of lactation. Hence, genetic parameters based on data sets from the same region and almost the same herds changed within a period of $7 \mathrm{yr}$, maybe due to changes in selection and mating strategies. Heritabilities for test-day SCS were in a narrow range in the course of DIM (i.e., between $\mathrm{h}^{2}$ $=0.10$ at DIM 40 and $\mathrm{h}^{2}=0.13$ at DIM 365).

The emphasis of this study was on the bivariate genetic relationships between selected claw disorders with test-day protein yield, and with test-day SCS by alterations of DIM. From the possible grid of pairwise $\mathrm{r}_{\mathrm{g}}$, Figures 1 to 6 focus on the whole DIM range for claw disorders, and on 1 selected test day early in lactation (d 20), 1 selected test day in the middle of lactation (d 160), and 1 selected test day late in lactation (d 300) for protein yield and SCS. Generally, $r_{g}$ between protein yield measured at d 20 with all measurements for DD were in a narrow interval between -0.15 and 0.05 (Figure 1). An unfavorable and positive $r_{g}$ with DD was observed directly after calving, but correlations were negative in the ongoing course of lactation. Accordingly, positive $r_{g}$ that indicate a genetic antagonism were found when correlating DD between d 80 and 160 with protein yield at d 160 . In causality, we conclude an undesired genetic effect of liability of DD on the production level, but without a recursive effect of protein 
yield on DD on the genetic scale. For test-day protein yield from $\mathrm{d} 300$, positive $\mathrm{r}_{\mathrm{g}}$ with $\mathrm{DD}$ were estimated during the peak phase of lactation (i.e., between $d 80$ and 150), with $\mathrm{r}_{\mathrm{g}}=0.20$. For identical test days from 6 to 305 DIM, $\mathrm{r}_{\mathrm{g}}$ between DD and protein yield varied in a narrow range from -0.09 to 0.09 . Interestingly, DD at d 160 was genetically positively correlated with protein yield from test d 160 to 365 (not shown). Hence, genes affecting susceptibility to DD during this peak phase of lactation simultaneously increased protein production in the middle and at the end of lactation. The relevance of this period of a natural energy deficiency on dairy cattle health from a phenotypic and genetic perspective was earlier discussed by Collard et al. (2000). Protein yield at d 300 was also positively correlated with DD measurements beyond 300 DIM. In the latter case, we postulate a lagged relationship from protein yield on DD. Effects of protein yield on DD, and recursive effects of DD on protein yield varied in the course of lactation. Such an alteration of genetic associations in the course of lactation can be inferred when applying RRM, but might be difficult to detect when using lactation records (e.g., Van Dorp et al., 2004), or only a single test-day observation (e.g., Koenig et al., 2005).

Structural equation models for such types of biological systems as proposed by Gianola and Sorensen (2004) are a further alternative to infer genetic relationships by considering the physiological background. With regard to structural equation models, König et al. (2008) introduced a first approach in the case of claw disorders, but they only focused on 2 specific test days in the first third of lactation. Consequently, they did not consider alteration of genetic parameters in the course of lactation as pointed out in the present study when applying RRM. Koeck et al. (2013) used the trait lameness from a substantial data set including 36,001 cows, and they applied random regression sire models to study genetic relationships with productivity (milk yield) in the course of lactation. In contrast to our study, $\mathrm{r}_{\mathrm{g}}$ were quite constant and ranged between 0.20 and 0.25 for identical DIM.

Protein yield at d 160 also revealed an antagonistic relationship with SU between DIM 100 and 365, but $\mathrm{r}_{\mathrm{g}}$ were weak and throughout lower than 0.20 (Figure 2). A lagged and antagonistic relationship was found for SU measured in the peak phase of lactation and protein yield from d 300. For this scenario, the highest correlation was of value 0.30 for SU at d 158 and protein yield at $\mathrm{d} 300$. The $\mathrm{r}_{\mathrm{g}}$ between protein yield at d 5 and corresponding test days for SU was negative, and only slightly antagonistic for SU between DIM 150 and 300. Again, lagged genetic relationships between claw disorders and productivity played a more important role for genetic antagonism than test days from an identical time span. For identical test days, $r_{g}$ were favorable from calving to DIM 120, with a minimal value of -0.25 (d 40); antagonistic between DIM 120 and DIM 315, with a maximal value of 0.22 (d 200); and again slightly favorable for the last period of lactation, with a minimal value of -0.07 (d 360).

Breeding on improved IH was associated with neutral or even increasing protein yield, and vice versa (Figure $3)$. Only IH late in lactation (DIM >345) was genetically antagonistically related to protein yield from $\mathrm{d}$ 160 and 300. However, for such a late stage of lactation, the reduced data set combined with small disease incidences should be kept in mind. Deviations of genetic parameters when applying RRM at the extreme ends

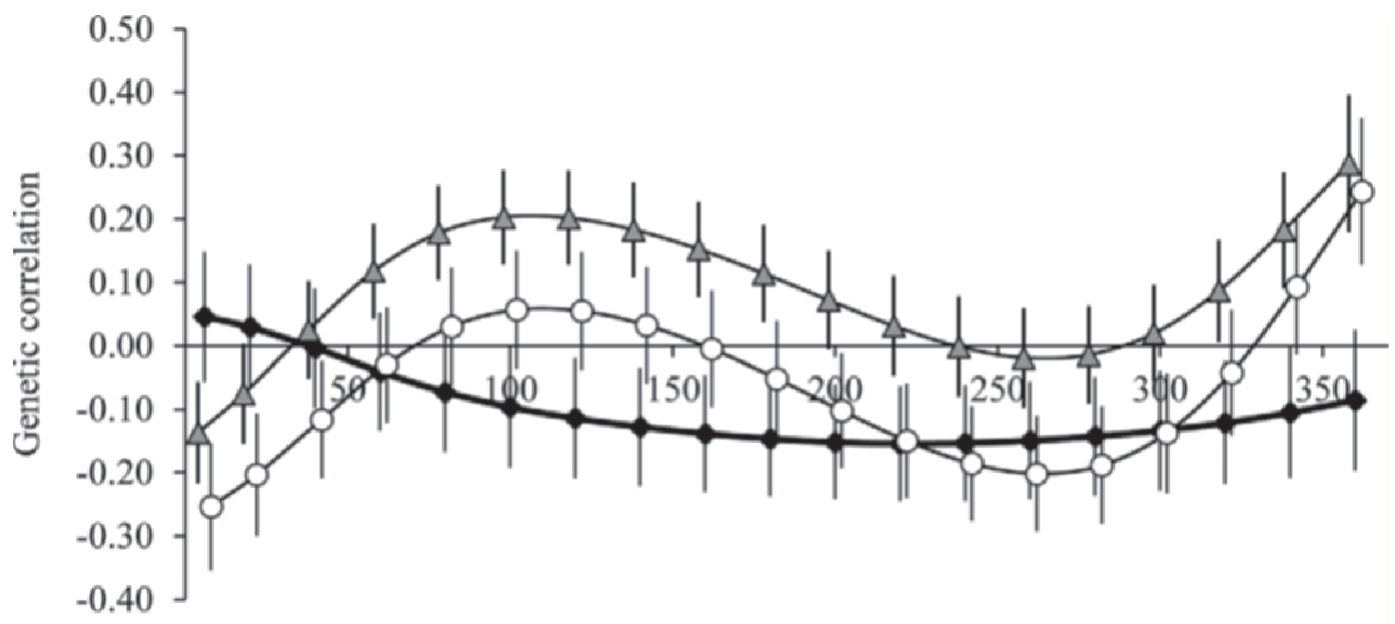

Days in milk

Figure 1. Posterior means for genetic correlations with corresponding SD (vertical lines) between daily liability to digital dermatitis and protein yield at d 20 (black diamonds), at d 160 (white circles), and at d 300 (gray triangles). 


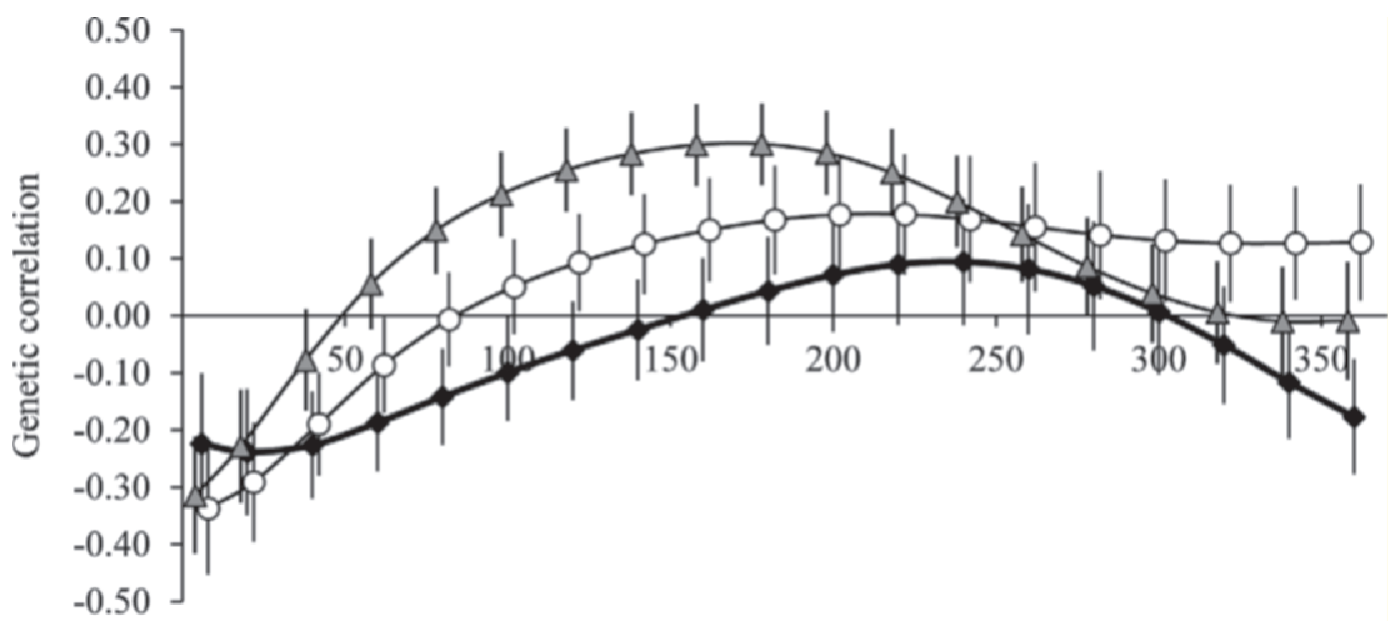

Days in milk

Figure 2. Posterior means for genetic correlations with corresponding SD (vertical lines) between daily liability to sole ulcer and protein yield at d 20 (black diamonds), at d 160 (white circles), and at d 300 (gray triangles).

of a time scale or a continuous environmental scale was pointed out in previous studies (e.g., recently by Brügemann et al., 2013). Genetic correlations between IH and protein yield for corresponding test days between DIM 6 and 300 were throughout negative and favorable, with a minimal value of -0.27 at $d 40$. Especially for IH, we did not find real evidence for genetic antagonistic relationships between claw health and productivity. Genetic correlations between claw disorders and productivity mostly close to zero or only slightly antagonistic were reported in previous studies using more robust and traditional bivariate or repeatability models (e.g., Koenig et al., 2005; Gernand et al., 2012). More relevance for genetic antagonisms might be attributed to diseases belonging to the categories of udder health or metabolism as outlined in a key paper addressing $\mathrm{r}_{\mathrm{g}}$ between diseases and milk yield by Simianer et al. (1991).

Daily $r_{g}$ between SCS and DD were mostly negative and close to zero, as illustrated for selected test days for SCS at d 20, 160, and 300 (Figure 4). Also for corresponding test days in the course of lactation, $\mathrm{r}_{\mathrm{g}}$ between DD and SCS were throughout negative in a range from -0.26 (d 5) to -0.09 (d 60). A negative correlation indicates that susceptibility to DD was associated with decreasing SCS. Hence, our results did not support the finding by Koenig et al. (2005), who concluded from a genetic perspective that "health disorders appear to

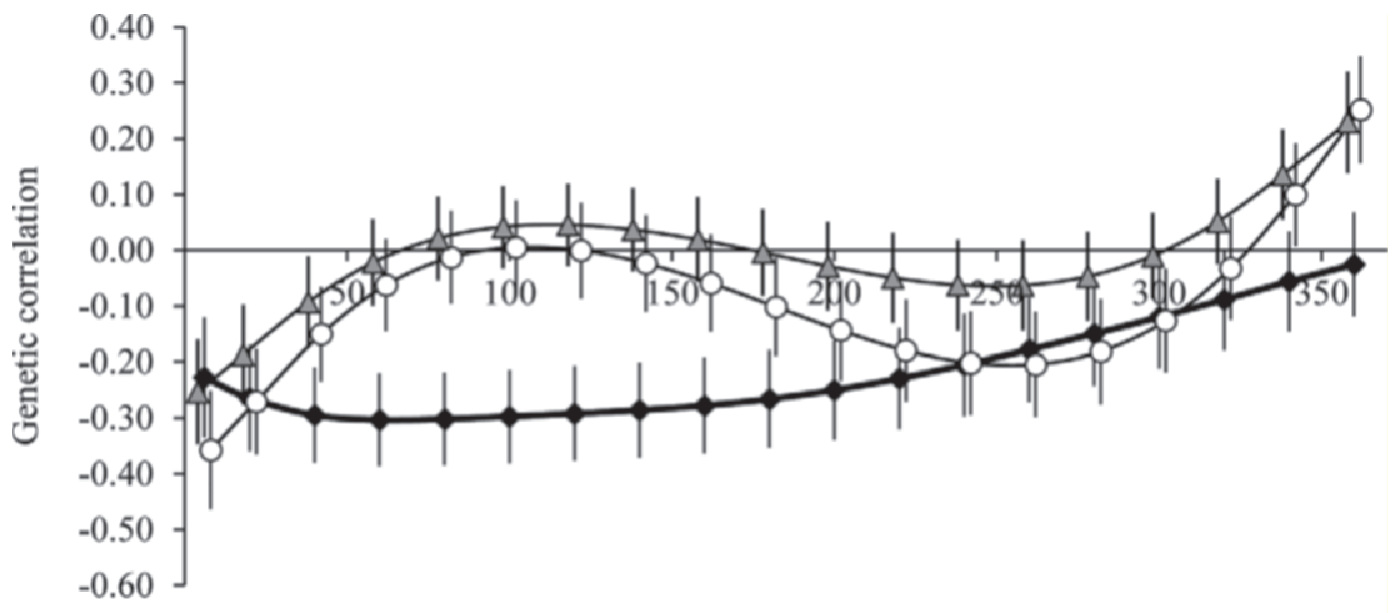

Days in milk

Figure 3. Posterior means for genetic correlations with corresponding SD (vertical lines) between daily liability to interdigital hyperplasia and protein yield at d 20 (black diamonds), at d 160 (white circles), and at d 300 (gray triangles). 


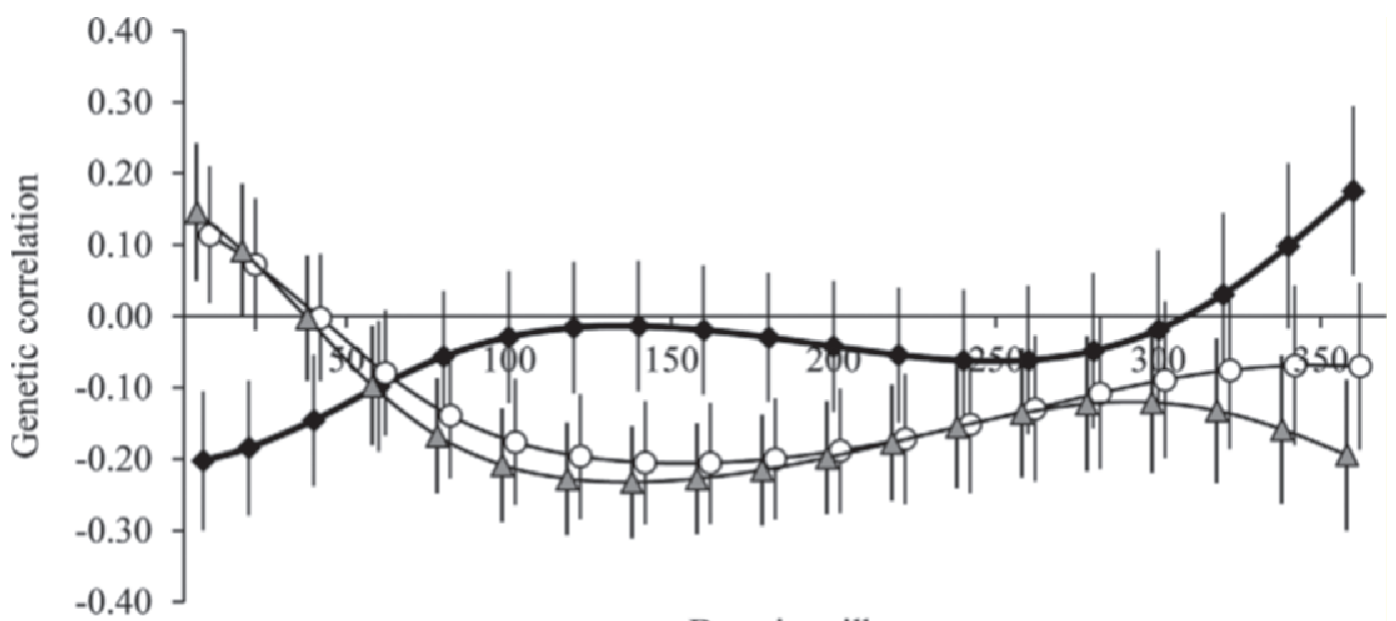

Days in milk

Figure 4. Posterior means for genetic correlations with corresponding SD (vertical lines) between daily liability to digital dermatitis and SCS at d 20 (black diamonds), at d 160 (white circles), and at d 300 (gray triangles).

occur in clusters." However, they only found a moderate $\mathrm{r}_{\mathrm{g}}$ between SU and SCS (0.28), whereas $\mathrm{r}_{\mathrm{g}}$ between SCS and DD, and SCS and IH, were close to zero, with values of 0.15 and 0.14 , respectively. Positive $r_{g}$ between different disorders might be due to a general immune response. The first studies with regard to natural antibodies and clinical mastitis on a quantitative genetic scale were conducted by Thompson-Crispi et al. (2012). The RRM study by Koeck et al. (2013) revealed positive $\mathrm{r}_{\mathrm{g}}$ between lameness and SCS in the course of lactation. In contrast, in our present study, only SCS from d 160 and 300 were positively correlated with DD during the first $40 \mathrm{~d}$ after calving.

The concept of a general immune response including udder and claw health was valid for SU with positive $r_{g}$ throughout in the course of lactation for identical DIM for SU and SCS ( $\mathrm{r}_{\mathrm{g}}$ varied between 0.03 at $\mathrm{d} 6$ and 0.18 at $\mathrm{d}$ 60) as well as for selected test days for SCS (Figure 5). Genetic correlations were highest between SCS from d 160 and 300 and SU during the first $100 \mathrm{~d}$ of lactation, with maximal values close to 0.40 . Different $r_{g}$ with SCS suggest a divergent genetic background of DD and SU. This phenomenon was described in previous studies, and verified by $r_{g}$ between DD and SU close to zero (e.g., 0.01 in the study by Gernand et al., 2013). Occurrence of DD and SU has different sources. For DD, specific bacteria were identified (Grund et al., 1995), whereas SU was described as a multifactorial disease with major effects of season, which reflect feeding and housing conditions (Sanders et al., 2009).

As found for DD and SU, SCS from d 160 and 300 was genetically positively correlated with $\mathrm{IH}$ in the early period of lactation directly after calving (Figure
6). Such a finding postulates a time-lagged relationship, as discussed for productivity and claw health. Genetic correlations between SCS at d 20 with IH in the course of lactation were quite constant and in a narrow range between 0.03 and 0.06 . Also, when analyzing identical test days for both traits $\mathrm{SCS}$ and $\mathrm{IH}, \mathrm{r}_{\mathrm{g}}$ were close to zero. The highest $r_{g}$ between SCS and IH were from $d$ 40 and 260 , with $r_{g}=0.11$. A comparable $r_{g}$ for the identical period within lactation of value 0.16 was estimated by Koenig et al. (2005).

Somatic cell score at d 20 was positively correlated with protein yield recorded between DIM 40 and 365 (Figure 7 ). The highest $\mathrm{r}_{\mathrm{g}}$ of 0.32 , indicating genetic antagonism, was estimated for SCS from d 5 and protein yield from d 260. Genetic correlations between SCS from d 160 with all test days for protein yield were close to zero, and even negative for identical test days for both traits late in lactation. For identical test days, the tendency for genetic antagonisms between protein yield and SCS was observed in the peak phase of lactation between DIM 40 and 180. Slight indications (but not statistically significant) for antagonistic effects between productivity and SCS only at the beginning of lactation are in accordance with previous studies based on data from large-scale dairy farms in the region of former East Germany (e.g., Koenig et al., 2005). For DIM late in lactation beyond 220 milking days, $\mathrm{r}_{\mathrm{g}}$ between milk yield and SCS were negative in a moderate range. This implies that high milk yield late in lactation was associated with a decrease in SCS on the genetic scale and, therefore, favorable from a breeding perspective.

Major results of the present study include a methodological or statistical component and practical 


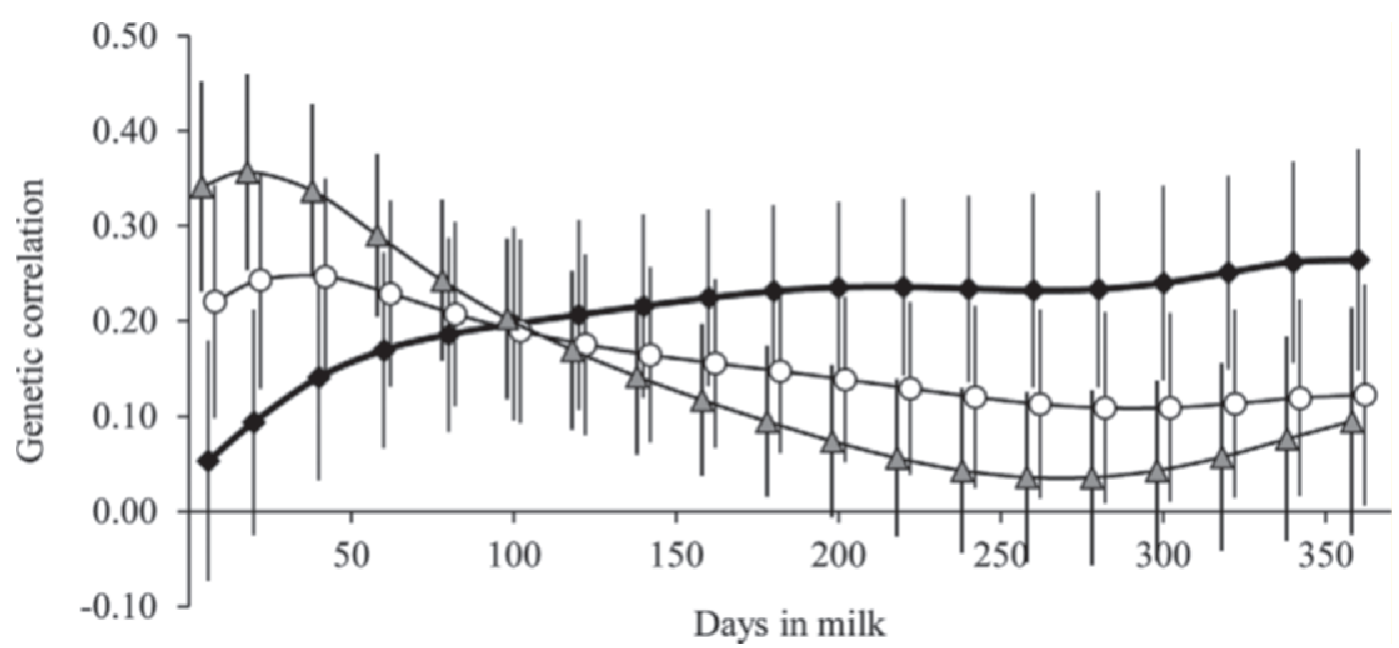

Figure 5. Posterior means for genetic correlations with corresponding SD (vertical lines) between daily liability to sole ulcer and SCS at d 20 (black diamonds), at d 160 (white circles), and at d 300 (gray triangles).

suggestions regarding breeding strategies. First, we showed the feasibility of threshold RRM applications to longitudinal binary data. Genetic parameters were in a reasonable parameter space; however, they were partly altered in the course of lactation. Alterations of genetic parameters in the course of lactation suggest different breeding strategies (i.e., the use of different sires to improve claw health at the beginning or at the end of lactation). Of practical relevance are $r_{g}$ between claw disorders and protein yield, which mostly were close to zero and which revealed quite high posterior standard deviations. We did not find substantial evidence for genetic antagonisms in the data set of selected cooperator herds. Hence, breeding on productivity does not impair DD, SU, or IH simultaneously, which implies the application of differentiated breeding strategies. Tendencies for antagonistic associations were found for the following pairwise analyses and time periods: between DD recorded at approximately DIM 100 and protein yield recorded at a late lactation stage, and between IH recorded at approximately DIM 160 and protein yield also from measurements in the late stage of lactation. Following the general aim to reduce disease incidences, direct selection strategies on claw disorders and including claw disorders in overall breeding goals are imperative. This recommendation is also based on moderate heritabilities on the underlying liability scale for disease traits in the course of lactation, which were higher than heritabilities for the health indicator SCS.

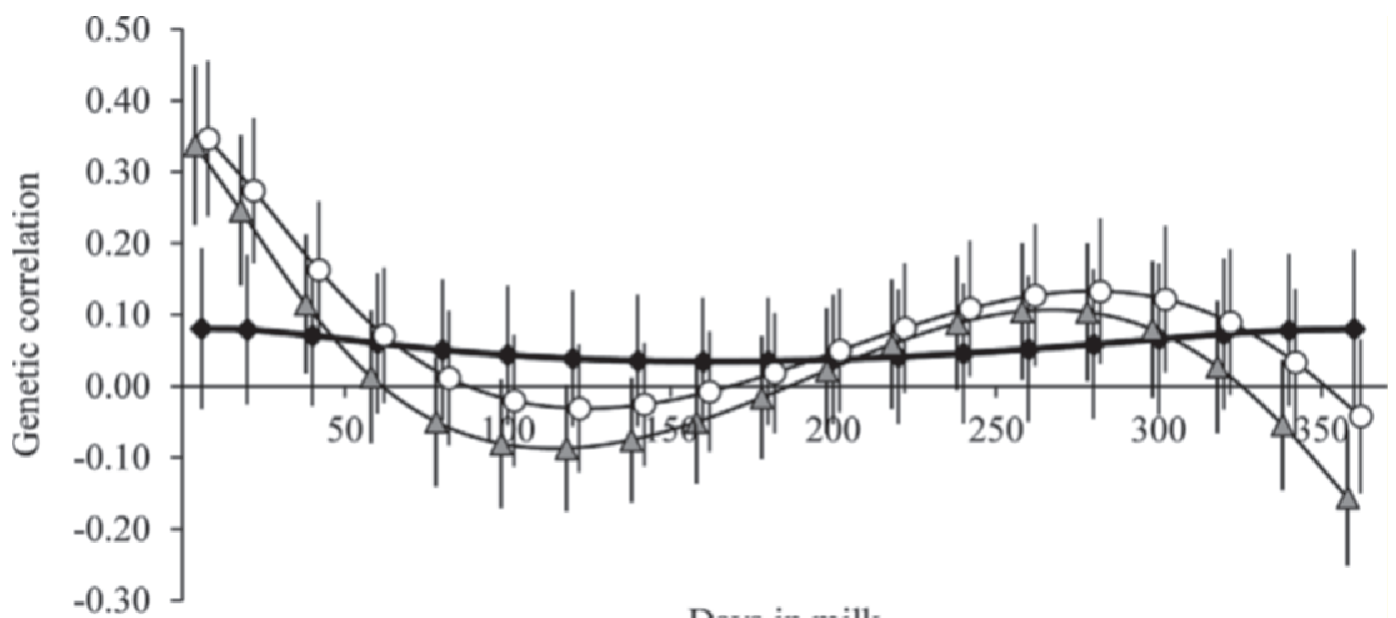

Figure 6. Posterior means for genetic correlations with corresponding SD (vertical lines) between daily liability to interdigital hyperplasia and SCS at d 20 (black diamonds), at d 160 (white circles), and at d 300 (gray triangles). 


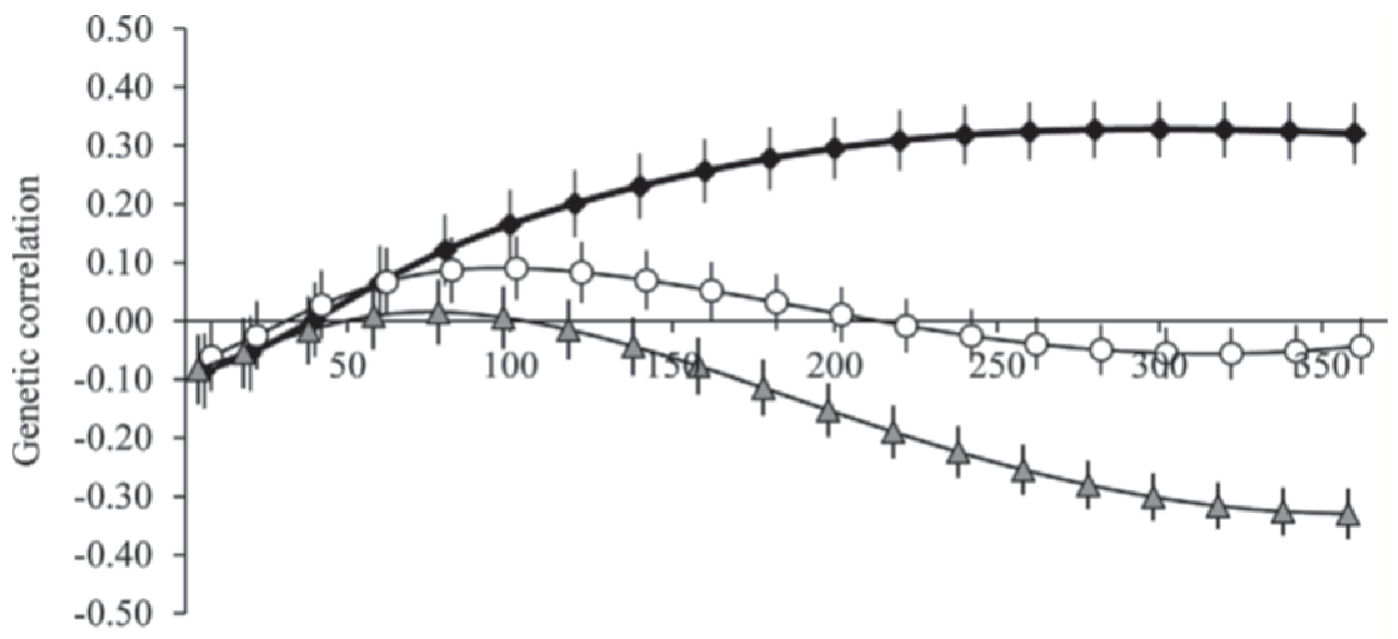

Days in milk

Figure 7. Posterior means for genetic correlations with corresponding SD (vertical lines) between daily protein yield and SCS at d 20 (black diamonds), at d 160 (white circles), and at d 300 (gray triangles).

\section{REFERENCES}

Brügemann, K., E. Gernand, U. U. von Borstel, and S. König. 2013. Application of random regression models to infer the genetic background and phenotypic trajectory of binary conception rate by alterations of temperature $\times$ humidity indices. Livest. Sci. 157:389-396. http://dx.doi.org/10.1016/j.livsci.2013.08.009.

Collard, B. L., P. J. Boettcher, J. C. M. Dekkers, D. Petitclerc, and L. R. Schaeffer. 2000. Relationships between energy balance and health traits of dairy cattle in early lactation. J. Dairy Sci. 83:2683-2690.

Feucker, W., and R. Staufenbiel. 2003. Zentraler Diagnoseschlüssel Rind. Accessed Mar. 16, 2010. http://www.portal-rind.de/index. php? module $=$ Downloads $\&$ func $=$ prep_hand_out\&lid $=17$.

Gernand, E., D. A. Döhne, and S. König. 2013. Genetic background of claw disorders in the course of lactation and their relationships with type traits. J. Anim. Breed. Genet. http://dx.doi. org/10.1111/jbg.12046.

Gernand, E., P. Rehbein, U.U. von Borstel, and S. König. 2012. Incidences of and genetic parameters for mastitis, claw disorders and common health traits recorded in dairy cattle contract herds. J. Dairy Sci. 95:2144-2156.

Gernand, E., R. Waßmuth, U. U. von Borstel, and S. König. 2007. Heterogeneity of variance components for production traits in large-scale dairy farms. Livest. Sci. 112:78-89.

Gianola, D., and D. Sorensen. 2004. Quantitative genetic models for describing simultaneous and recursive relationships between phenotypes. Genetics 167:1407-1424.

Grund, S., H. Nattermann, and F. Horsch. 1995. Electron microscopic detection of spirochetes in dermatitis digitalis of cattle. Zentralbl. Veterinärmed. B 42:533-542. (Article in German).
Koeck, A., F. Miglior, S. Loker, D. F. Kelton, and F. S. Schenkel. 2013. Genetic relationships of mastitis, cystic ovaries and lameness with milk yield and somatic cell score in first lactation Canadian Holstein. Dairy Cattle Breeding and Genetics Committee Agenda, February 13, 2013. Accessed Sep. 3, 2013. http://cgil.uoguelph.ca/ dcbgc/Agenda1302/agenda1302.htm.

Koenig, S., A. R. Sharifi, H. Wentrot, D. Landmann, M. Eise, and H. Simianer. 2005. Genetic parameters of claw and foot disorders estimated with logistic models. J. Dairy Sci. 88:3316-3325.

König, S., X.-L. Wu, D. Gianola, B. Heringstad, and H. Simianer. 2008. Exploration of relationships between claw disorders and milk yield in Holstein cows via recursive linear and threshold models. J. Dairy Sci. 91:395-406.

Lyons, D. T., A. E. Freeman, and A. L. Luck. 1991. Genetics of health traits in cattle. J. Dairy Sci. 74:1092-1100.

Madsen, P., and J. Jensen. 2008. A user's guide to DMU. A package for analyzing multivariate mixed models. Version 6 , release 4.7. Danish Inst. of Agric. Sci., Tjele, Denmark.

Sanders, A. H., J. K. Shearer, and A. De Vries. 2009. Seasonal incidence of lameness and risk factors associated with thin soles, white line disease, ulcers, and sole punctures in dairy cattle. J. Dairy Sci. 92:3165-3174.

Simianer, H., H. Solbu, and L. R. Schaeffer. 1991. Estimated genetic correlations between disease and yield traits in dairy cattle. J. Dairy Sci. 74:4358-4365.

Thompson-Crispi, K. A., A. Sewalem, F. Miglior, and B. A. Mallard. 2012. Genetic parameters of adaptive immune response traits in Canadian Holstein. J. Dairy Sci. 95:401-409.

Van Dorp, T. E., P. Boettcher, and L. R. Schaeffer. 2004. Genetics of locomotion. Livest. Prod. Sci. 90:247-253. 